Article

\title{
Resistance to Ultraviolet Aging of Nano-SiO Rubber Powder Compound Modified Asphalt
}

\author{
Guoping Qian, Changdong Yang, Haidong Huang, Xiangbing Gong * and Huanan Yu(D) \\ State Engineering Laboratory of Highway Maintenance Technology, Changsha University of Science and \\ Technology, Changsha 410114, China; guopingqian@csust.edu.cn (G.Q.); ycd960203@163.com (C.Y.); \\ haidong@163.com (H.H.); huanan.yu@csust.edu.cn (H.Y.) \\ * Correspondence: xbgong@csust.edu.cn; Tel.: +86-1868-480-2961
}

Received: 3 October 2020; Accepted: 9 November 2020; Published: 10 November 2020

check for updates

\begin{abstract}
Ultraviolet (UV) aging degrades the life span of asphalt pavement, nanomaterials used as modifiers exhibit good shielding function on UV light, but generally degrade the low-temperature property of asphalt, a compound modification was found to be a solution. In this study, nano- $\mathrm{SiO}_{2}$ and rubber powder were blended together with base asphalt to prepare compound modified asphalt. Compound modified asphalt with different blending dosages were subjected to UV light via a self-made UV aging simulation chamber. Basic performance tests and rheological tests were conducted including the UV aging influence. An optimum compound ratio was finally recommended based on the goal to remove the adverse effect of nano- $\mathrm{SiO}_{2}$ on the thermal cracking. Results show that the anti-UV aging property of asphalt is improved obviously due to the blocking function of nano- $\mathrm{SiO}_{2}$ and carbon black in rubber powder, and the enhancing effect of nano- $\mathrm{SiO}_{2}$ is found to be the most significant.
\end{abstract}

Keywords: compound modification; ultraviolet aging; rheological properties; nano-SiO ${ }_{2}$; rubber powder

\section{Introduction}

Asphalt pavement is directly exposed to external factors during its service period, such as sunlight, oxygen, water, heat, and driving load. Factors generally lead to properties degradation of paving material and service issues of pavement performance [1-4]. Among all short-term and long-term damages, aging commonly occurs at the surface layer and brings several distresses as aging develops [5]. In general, aging type of asphalt materials is divided into thermal oxygen aging and photooxidative aging. The effect of aging on the performance of asphalt is very huge, aging will make the asphalt hard and brittle, and then easy cracking degrades the road service capacity [6]. In some areas with strong ultraviolet (UV) light, UV aging becomes a predominant fact and seriously affects the rheological properties of asphalt and life span of asphalt pavement [7,8]. However, in current aging resistance evaluation specification, only thermal oxygen aging is included except for UV aging. Qian et al. [5,7] have been studying the UV aging degradation via developing a UV light apparatus to simulate the UV aging in pavement surface layer. Therefore, the UV light can be effectively included in laboratory tests to evaluate resistance to UV aging of asphalt materials.

In recent years, nanomaterials have been widely used as modifiers to enhance materials' properties. Cheraghian et al. [9] utilized nanomaterials to improve the rheological and fluid loss properties of water-based drilling fluids. In asphalt materials, nanomaterials not only improve the properties of asphalt but also greatly improve the anti-UV aging performance of asphalt [10-12]. Asphalt modified with nanomaterials and other chemical modifiers shows strong resistance against high-temperature rutting and low-temperature cracking [13]. Fini et al. [14] studied the effect of nano- $\mathrm{SiO}_{2}$ on rheological 
and aging properties of asphalt, results show that nano- $\mathrm{SiO}_{2}$ improves the fundamental and anti-aging properties of asphalt. Cheraghian et al. [15] used dynamic shear rheometer (DSR) and Fourier transform infrared (FT-IR) spectroscopy to study modification method by adding clay and nano-SiO $\mathrm{S}_{2}$. Results present that clay and nano- $\mathrm{SiO}_{2}$ can improve the anti-UV aging performance of asphalt. Yao et al. [16] explored the rheological properties and molecular structure of nano-SiO $\mathrm{S}_{2}$ modified asphalt, scholars conducted aging tests on nano- $\mathrm{SiO}_{2}$ modified asphalt. It was found that the viscosity decreased slightly, and the low-temperature performance decreased, but the anti-aging property significantly improved. Shafabakhsh et al. [17] prepared modified asphalt mixtures with different nano- $\mathrm{TiO}_{2}$ contents, it was told that nano- $\mathrm{TiO}_{2}$ leaded great enhancement on permanent deformation resistance and fatigue life of asphalt mixtures. Related studies $[12,18,19]$ exhibit that the nano- $\mathrm{SiO}_{2}$ and nano- $\mathrm{TiO}_{2}$ can improve the anti-aging properties of asphalt but may have a negative effect on the low-temperature properties of asphalt.

Chemical additives have been used to improve the road performance of base asphalt for many decades. The low-temperature cracking property and high-temperature stability of modified asphalt are superior to non-modified asphalt $[18,20]$. Additionally, application of waste rubber on the road can solve the problem of disposal of used tires and environment issues [21]. Li et al. [22] conducted thermal oxygen aging tests based on the analysis of the composition and structure, the thermal oxygen aging mechanism of rubber powder modified asphalt was discussed in this study, results indicate that rubber powder modified asphalt has an excellent anti-aging performance. Pang et al. [23] blended an anti-UV aging double hydroxide with rubber powder modified asphalt to study the anti-aging characteristic of compound modified asphalt, the short-term and long-term aging data imply that the modified asphalt has better UV aging resistance. Xiao et al. [24] carried out high-performance gel chromatography (HP-GPC) test on long-term aging samples of rubber powder modified asphalt, base asphalt and styrene-butadiene-styrene (SBS) modified asphalt to analyze the molecular distribution (MSD) of asphalt subjected to aging, it was found that the macromolecules of rubber asphalt showed the least increase in proportion, rubber powder is proved to improve the low-temperature cracking and aging resistance of asphalt.

Currently, nano- $\mathrm{SiO}_{2}$ has been widely applied to make modified asphalt. Different sources, different dosages, and different blending methods of modified asphalt will affect the rheological properties and aging properties of asphalt [25]. Nano- $\mathrm{SiO}_{2}$ presents a special silane tetrahedral structure known as agglomeration [26,27]. Generally, the high-temperature performance of nano- $\mathrm{SiO}_{2}$ modified asphalt is better than base asphalt, and the high-temperature performance of modified asphalt is more excellent with the increase of nano- $\mathrm{SiO}_{2}$ content. However, the higher nano- $\mathrm{SiO}_{2}$ amount does not mean better performance [28]. Nano- $\mathrm{SiO}_{2}$ was proved to affect the low-temperature performance of the modified asphalt [29-31]. As a waste material, rubber powder modified asphalt shows successful application on asphalt modification. The amount of waste rubber powder in rubber asphalt is generally between $5 \%$ and $30 \%$ based on related studies [32,33]. Results tell that $20 \%$ rubber powder improves the high and low-temperature properties, anti-aging properties, and temperature sensitivity of asphalt $[34,35]$. However, the fatigue life of the rubber powder modified asphalt mixture increased with the crumb rubber content, but only to a certain percent before it started to decrease again [36].

Therefore, to eliminate the effect of nano- $\mathrm{SiO}_{2}$ on the low-temperature property of asphalt, this study selects the compound modification method by using rubber powder as a topic. In order to evaluate the comprehensive properties of asphalt used in strong UV sunlight regions, this study mainly aims at anti-UV aging capacity as well as the fundamental performances of nano- $\mathrm{SiO}_{2}$ and rubber powder compound modified asphalt especially the low-temperature property. It firstly conducted property evaluation of asphalt under different compounding ratios before aging by conventional performance tests and rheological property tests. Then, a self-made UV environment device was used to simulate the UV aging, and the anti-UV aging property of modified asphalt with different compound ratios were analyzed. The main objective of this study is to explore the optimum compounding ratio of 
nano- $\mathrm{SiO}_{2}$ and rubber powder, the predominant goal is to remove the disadvantage of nano- $\mathrm{SiO}_{2}$ on low-temperature cracking property without degradation of other performances. The other objective is to assess the UV aging resistance of compound modified asphalt and distinguish the internal function of rubber powder and nano-SiO ${ }_{2}$.

\section{Materials and Methods}

\subsection{Physical Properties of Raw Materials}

This study selected a type of nano-SiO 2 produced by Zhongkexing Co., Ltd. (Wuhan, China), and its physical properties are shown in Table 1.

Table 1. Physical properties of nano-SiO 2 .

\begin{tabular}{ccc}
\hline Items & Unit & Testing Result \\
\hline Outer diameter & $\mathrm{nm}$ & $10 \sim 20$ \\
Purity & weight, $\%$ & $>99.8$ \\
Molecular weight & - & 60.08 \\
PH & - & $5 \sim 7$ \\
Tap density & $\mathrm{m}^{2} / \mathrm{g}$ & 250 \\
\hline
\end{tabular}

Rubber powder is a kind of waste rubber powder produced by Zhejiang Green Ring Co., Ltd. (Zhejiang, China), and its physical properties are shown in Table 2.

Table 2. Physical properties of 80\# mesh waste rubber powder (\%).

\begin{tabular}{ccccccc}
\hline Items & $\begin{array}{c}\text { Passing } \\
\text { Rate }\end{array}$ & $\begin{array}{c}\text { Water } \\
\text { Content }\end{array}$ & $\begin{array}{c}\text { Ash } \\
\text { Content }\end{array}$ & $\begin{array}{c}\text { Metal } \\
\text { Content }\end{array}$ & $\begin{array}{c}\text { Carbon } \\
\text { Black } \\
\text { Content }\end{array}$ & $\begin{array}{c}\text { Rubber } \\
\text { Hydrocarbon }\end{array}$ \\
\hline Testing results & 97 & 0.72 & 7 & 0.004 & 30 & 34 \\
$\begin{array}{c}\text { Limit } \\
\text { Specification }\end{array}$ & $>96$ & $<1$ & $<8$ & $<0.01$ & $>28$ & $>30$ \\
code & GB/T1 & GB/T1 & GB/T4 & GB/T1 & GB/T1 & GB/T1 \\
\hline
\end{tabular}

The base asphalt is 70\#A grade petroleum asphalt produced by Sinopec Maoming Branch (Guangdong, China). The physical properties are shown in Table 3.

Table 3. Physical properties of 70\#A asphalt.

\begin{tabular}{cccc}
\hline Items & Technical Limit & Test Result & Specification Code \\
\hline Penetration $\left(25^{\circ} \mathrm{C}, 100 \mathrm{~g}, 5 \mathrm{~s}\right), 0.1 \mathrm{~mm}$ & $60 \sim 80$ & 65.2 & T0604 \\
Penetration index & $-1.5 \sim+1.0$ & 0.73 & $\mathrm{~T} 0604$ \\
Softening point, ${ }^{\circ} \mathrm{C}$ & $\geq 46$ & 48 & $\mathrm{~T} 0606$ \\
Density $\left(15^{\circ} \mathrm{C}\right), \mathrm{g} / \mathrm{cm}^{3}$ & - & 1.034 & $\mathrm{~T} 0603$ \\
Ductility $\left(15^{\circ} \mathrm{C}, 5 \mathrm{~cm} / \mathrm{min}\right), \mathrm{cm}$ & $\geq 100$ & $>100$ & $\mathrm{~T} 0605$ \\
Wax content, $\%$ & $\leq 2.2$ & 2 & $\mathrm{~T} 0615$ \\
Dynamic viscosity $\left(60^{\circ} \mathrm{C}\right), \mathrm{Pa} \cdot \mathrm{s}$ & $\geq 180$ & 215 & $\mathrm{~T} 0620$ \\
\hline
\end{tabular}

All raw materials' properties meet the industrial specification requirement of China.

\subsection{Preparation of Modified Asphalt}

According to the literature review, the dosage range of nano- $\mathrm{SiO}_{2}$ is $3 \sim 5 \%$, the amount of $80 \#$ mesh rubber powder used in this study is chosen to be $12 \sim 20 \%$ The design of the compound modification is controlled by the control variable method. For the convenience to label the experimental group, 
" $3 \%$ nano- $\mathrm{SiO}_{2}$ " is abbreviated as " $3 S^{\prime}$, " $20 \%$ rubber powder" is abbreviated as " $20 \mathrm{C}$ ", and the other contrasting groups follow this rule. The high-speed shearing method was used to prepare modified asphalt. First, the base asphalt was melted at $170{ }^{\circ} \mathrm{C}$ and weighed a certain mass. Second, $\mathrm{Nano}-\mathrm{SiO}_{2}$ and rubber powder mixed added into the base asphalt at $170{ }^{\circ} \mathrm{C}$ respectively, and artificially stirred for 20min at approximate $180^{\circ} \mathrm{C}$. Finally, a high-speed shear apparatus was used to grind modifiers and asphalt for $60 \mathrm{~min}$ at around $180{ }^{\circ} \mathrm{C}$ and with a speed of $5000 \mathrm{rpm}$.

\subsection{Property Evaluation Tests and Aging Tests}

In this study, the basic physical properties of the original asphalt without UV aging and the UV aged asphalt were tested via fully automatic asphalt softening point tester, digital ductility tester, HAILEA water bath tester manufactured by Infra Test Company of Germany (Dresden, Germany), and an automatic asphalt penetration tester manufactured by Chenxin Company of Zhejiang Province (Zhejiang, China). The Dynamic shear rheometer test of experimental samples was carried out by the dynamic shear rheometer (DSR) produced by Anton Paar Company (Graz, Austria) to study the high-temperature stability. A $\Phi 25 \mathrm{~mm}$ parallel plate was used to conduct temperature sweep and rutting factor test with a fixed frequency equal to $10 \mathrm{rad} / \mathrm{s}$. Complex modulus $\left(G^{*}\right)$ is ratio of peak stress to the peak strain in harmonic sinusoidal oscillation, which can be used as an index to express the dynamic shearing responses of asphalt. The phase angle $(\delta)$, complex shear modulus $\left(G^{*}\right)$, and rutting factor $\left(G^{*} / \sin \delta\right)$ were measured finally. The low-Temperature property was studied by using the bending beam rheometer (BBR) produced by Cannon Company (Cranberry Township, PA, USA). The loading time was equal to $240 \mathrm{~s}$. Load and deformation data were collected at $8 \mathrm{~s}, 15 \mathrm{~s}$, $30 \mathrm{~s}, 60 \mathrm{~s}, 120 \mathrm{~s}$, and $240 \mathrm{~s}$. The stiffness modulus $(S)$ was measured by obtaining the displacement of asphalt beams $(127 \mathrm{~mm} \times 6.35 \mathrm{~mm} \times 12.7 \mathrm{~mm})$ at $-12{ }^{\circ} \mathrm{C},-18{ }^{\circ} \mathrm{C}$, and $-24^{\circ} \mathrm{C}$. Referring to a Chinese specification named as "Asphalt Rubber For Highway Engineering" (JT/T 798-2011) [37], the $180^{\circ} \mathrm{C}$ Brookfield viscosity was investigate associated with rubber powder asphalt.

The UV aging test on asphalt was simulated by using a self-made UV environment apparatus (Changsha University of Science and Technology, Changsha, China). The temperature of sample chamber was controlled at $25^{\circ} \mathrm{C}$, the intensity of UV light was $14.2 \mathrm{~mW} / \mathrm{cm}^{2}$. The exposed duration of samples was 7 days, which was equivalent to the UV radiation amount of three months in northwestern China known well as the high UV light intensity region. The self-made apparatus is presented in Figure 1, it consists of a UV light, a sample chamber, a light intensity controller a temperature controller, and a light intensity tester. The UV light has four rows, 10 UV-LED beads are installed in each row with filters inside to ensure the occupancy of UV light. There are cooling fans, heater, humidity and temperature testers inside the chamber. The light intensity controller can adjust the intensity of UV light and display accumulated duration, UV light intensity in the chamber can be measured by the light intensity tester. In this study, a circular disc with a diameter of $140 \mathrm{~mm}$ is used as the asphalt sample tray, and the thickness of each binder sample is $1.5 \mathrm{~mm}$. According to the formula (mass = bottom area $x$ thickness $x$ density), the mass of asphalt required for each sample was calculated and poured into the asphalt sample tray. After the leveling of asphalt surface, samples were cooled to a room temperature on a platform, finally samples were prepared to be exposed to the UV light via the self-made UV environment apparatus, each experimental group has five samples. 


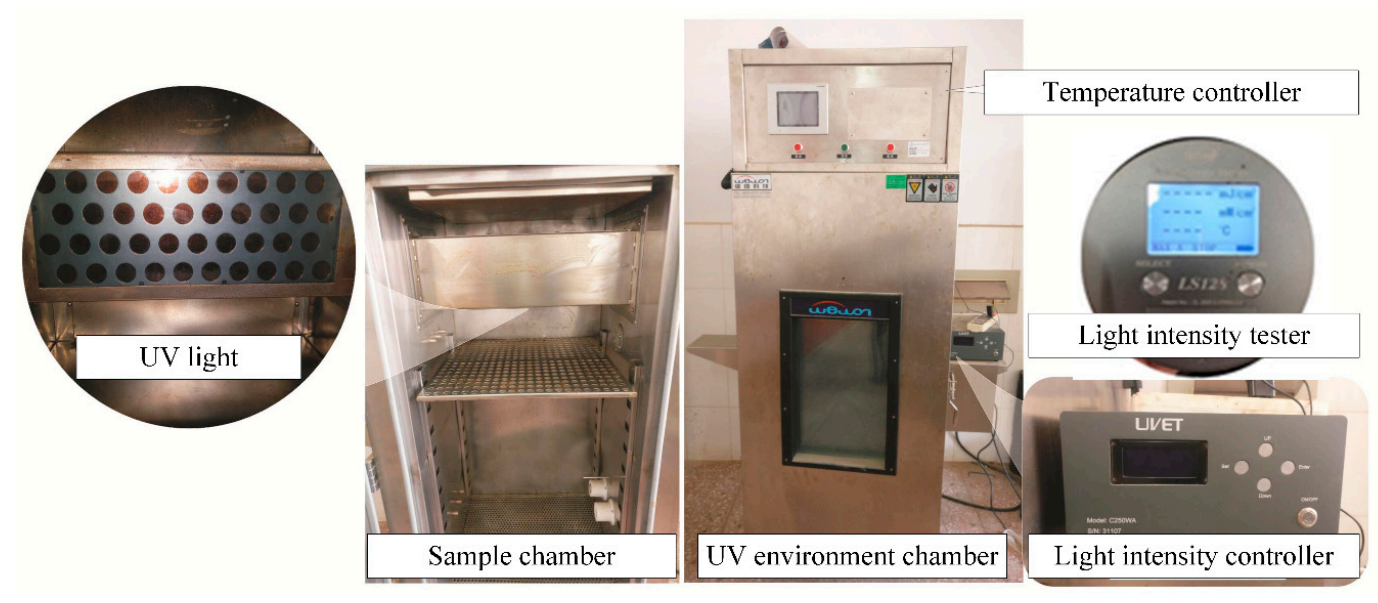

Figure 1. Self-made UV environment apparatus.

\subsection{Evaluation Indexes of UV Aging}

The UV aging degree of asphalt can be expressed by evaluation indexes, which are defined by the fluctuations of physical characteristics of testing samples. In this study, the basic properties and rheological properties of asphalt before and after UV aging were used to evaluate the UV aging resistance of asphalt, including the change of softening point $\left(C_{s p}\right)$, the change percent of penetration $\left(P_{\text {age }}\right)$, Brookfield viscosity aging index $\left(V_{\text {age }}\right)$, complex modulus aging index $\left(C_{\text {age }}\right)$, and stiffness modulus aging index $\left(S_{\text {age }}\right)$. All calculation formulas of indexes are expressed as follows:

$$
\begin{gathered}
C_{s p}=\text { softening point }{ }^{* *}-\text { softening point }{ }^{*} \\
P_{\text {age }}=\frac{\text { penetration }^{* *}}{\text { penetration }} \\
V_{\text {age }}=\frac{\text { viscosity aging }^{* *}-\text { viscosity aging }^{*}}{\text { viscosity aging }^{*}} \\
C_{\text {age }}=\frac{\text { complex modulus }^{* *}}{\text { comples modulus }^{*}} \\
S_{\text {age }}=\frac{\text { stiffiness modulus }^{* *}}{\text { stiffiness modulus }^{*}}
\end{gathered}
$$

where, ${ }^{*}$ means before aging, ${ }^{* *}$ means after aging.

\section{Results Discussion of Original Asphalt without UV Aging}

\subsection{Fundamental Properties}

From the softening point results, Figure 2 shows that the base asphalt has the smallest softening point, which might lead to the worst high-temperature performance. Whether single-doped nano-SiO or single-doped rubber powder, the softening point of the $4 \mathrm{~S}$ and $20 \mathrm{C}$ increases obviously, especially the softening point of the $20 \mathrm{C}$ is $14^{\circ} \mathrm{C}$ higher than that of the base asphalt. This finding implies that nano- $\mathrm{SiO}_{2}$ and rubber powder have a positive effect on the high-temperature stability of asphalt. The penetration of modified asphalt at $25^{\circ} \mathrm{C}$ drops compared with the base asphalt, which means that modifiers increase the consistence of the asphalt. Thus, the high-temperature stability of asphalt is improved. The penetration of $4 \mathrm{~S} 12 \mathrm{C}$ is the lowest, the value is $1.94 \mathrm{~mm}$ lower than the base asphalt. Compared with single-doped modified asphalt, the penetration of compound modified asphalt is lower, two types of modifiers seem to play an enhancing role in improving the consistence of asphalt. 


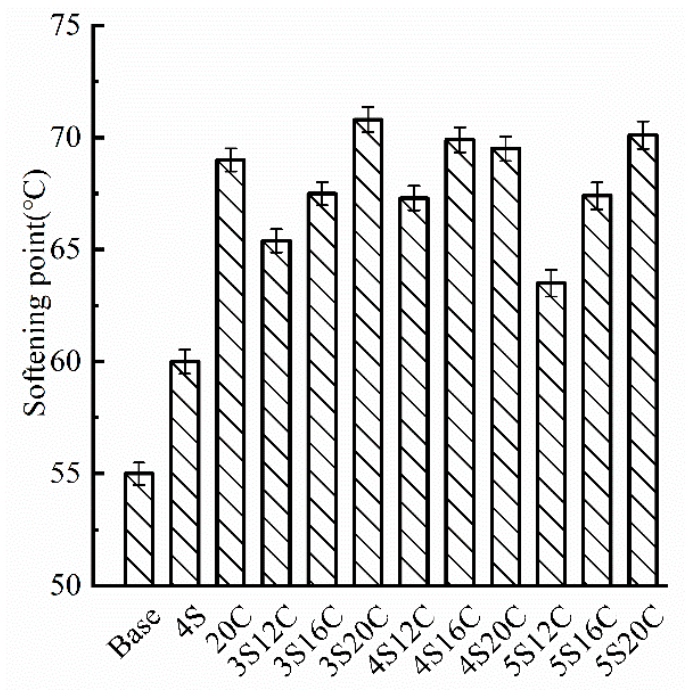

(a)

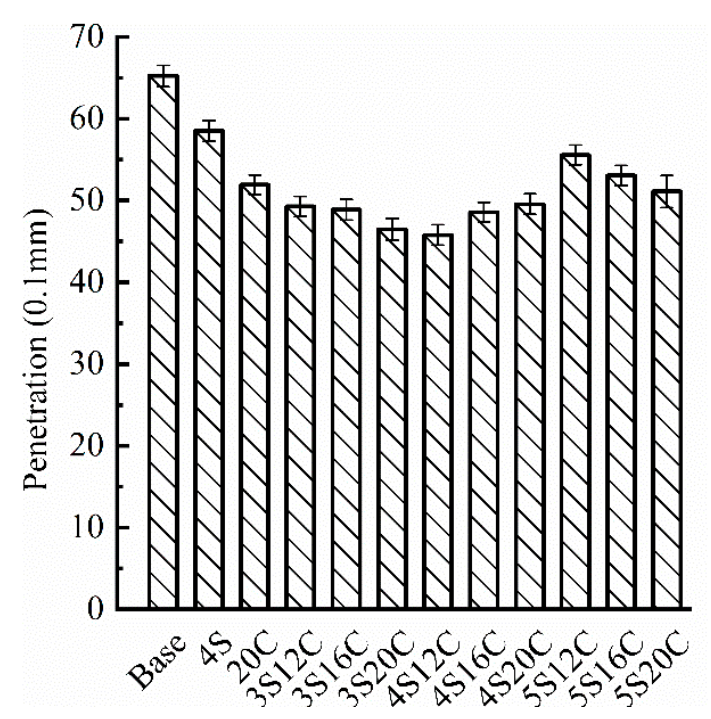

(b)

Figure 2. Basic physical properties testing results: (a) softening point, and (b) penetration.

\subsection{Rheological Properties}

\subsubsection{Brookfield Viscosity Test}

According to the industrial standard (JT/T 798-2011) in China, named as "Asphalt Rubber For Highway Engineering" [37], the results of Brookfield viscosity $\left(180^{\circ} \mathrm{C}\right)$ test are shown in Figure 3.

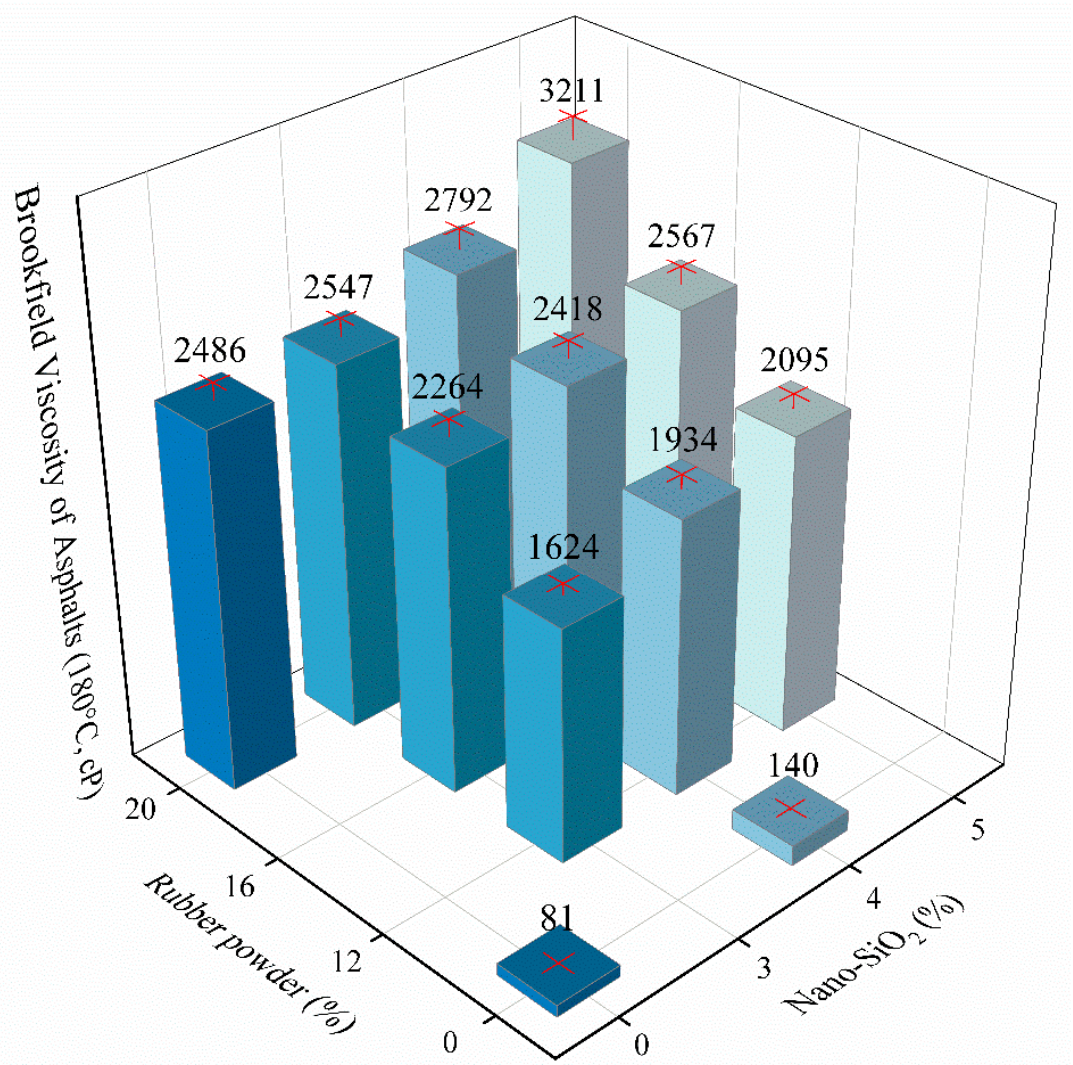

Figure 3. Brookfield viscosity of different experimental groups $\left(180^{\circ} \mathrm{C}, \mathrm{cP}\right)$. 
Viscosity of the base asphalt is the smallest, and modifiers increases the viscosity of asphalt. The incorporation of $4 \%$ nano- $\mathrm{SiO}_{2}$ does not increase the viscosity noticeably, because of only $59 \mathrm{cP}$ increment with regard to the base asphalt. Otherwise, the incorporation of $20 \%$ rubber powder greatly increases the viscosity. The testing value rises from $81 \mathrm{cP}$ to $2486 \mathrm{cP}$, because the rubber powder absorbs the asphaltene in the asphalt and forms cross-linked spatial network. Figure 3 shows that the viscosity of 5S20C is the highest among all asphalt samples, and its value is $3211 \mathrm{cP}$. However, increase of viscosity will make workability worse. With regard to compound modified asphalt, the viscosity rises with the growth of modifier content. The increment of $4 \mathrm{~S} 20 \mathrm{C}$ and $20 \mathrm{C}$ is larger than that of $4 \mathrm{~S}$ and base asphalt, due to the reason that nano- $\mathrm{SiO}_{2}$ fills the network structure of rubber powder modified asphalt rubber. Therefore, compound modification is proved to easily strengthen the viscosity of asphalt.

\subsubsection{Dynamic Shear Rheometer Test}

According to AASHTO M320 specification, rutting factor is the ratio of complex modulus to sine of phase angle at a frequency of $10 \mathrm{rad} / \mathrm{s}$, which can be used as an index to evaluate the high temperature performance of asphalt. Results of rutting factor for each contrasting group are listed in Figure 4, the coefficient of variation of all data is less than $10 \%$.

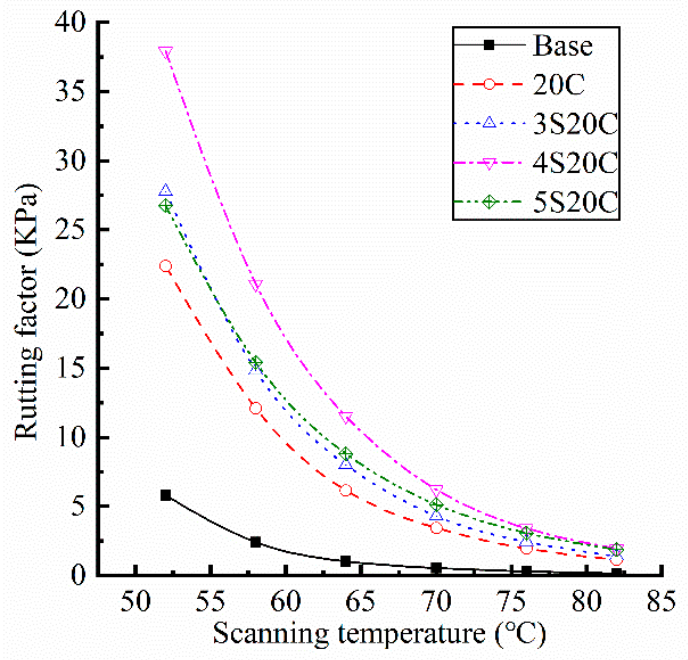

(a)

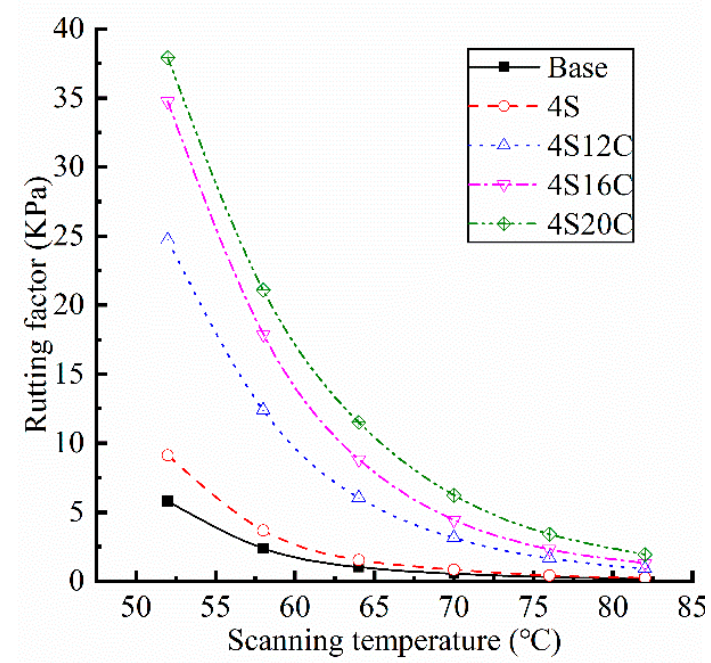

(b)

Figure 4. Rutting factors of asphalt: (a) with different nano- $\mathrm{SiO}_{2}$ content, and (b) with different rubber powder content.

Figure 4 indicates that rutting factors of the single-doped modified asphalt (4S and 20C) are higher than that of base asphalt. The rutting factor of 4S20C is the largest in the compound modified asphalt, which is nearly five time larger than that of the base asphalt. The base asphalt has the poorest high-temperature displacement resistance due to its smallest rutting factor. The incorporation of $20 \%$ rubber powder greatly improves the high-temperature stability of asphalt. With the incorporation of nano- $\mathrm{SiO}_{2}$, the rutting factor of asphalt shows a trend of increase first and then decrease. When the content of nano- $\mathrm{SiO}_{2}$ is $4 \%$ in Figure $4 \mathrm{a}$, the rutting factor reaches the maximum. Figure $4 \mathrm{~b}$ shows that the rutting factor exhibits a very obvious improvement with the incorporation of rubber powder.

\subsubsection{Bending Beam Rheometer Test}

Stiffness modulus ( $S$ ) of each group can be seen in Figure 5. The stiffness modulus increases as the test temperature decreases, the creep rate decreases as the test temperature decreases. This fact means that the asphalt becomes hard and brittle as the temperature decreases, and brittle cracking is likely to occur under external force. 


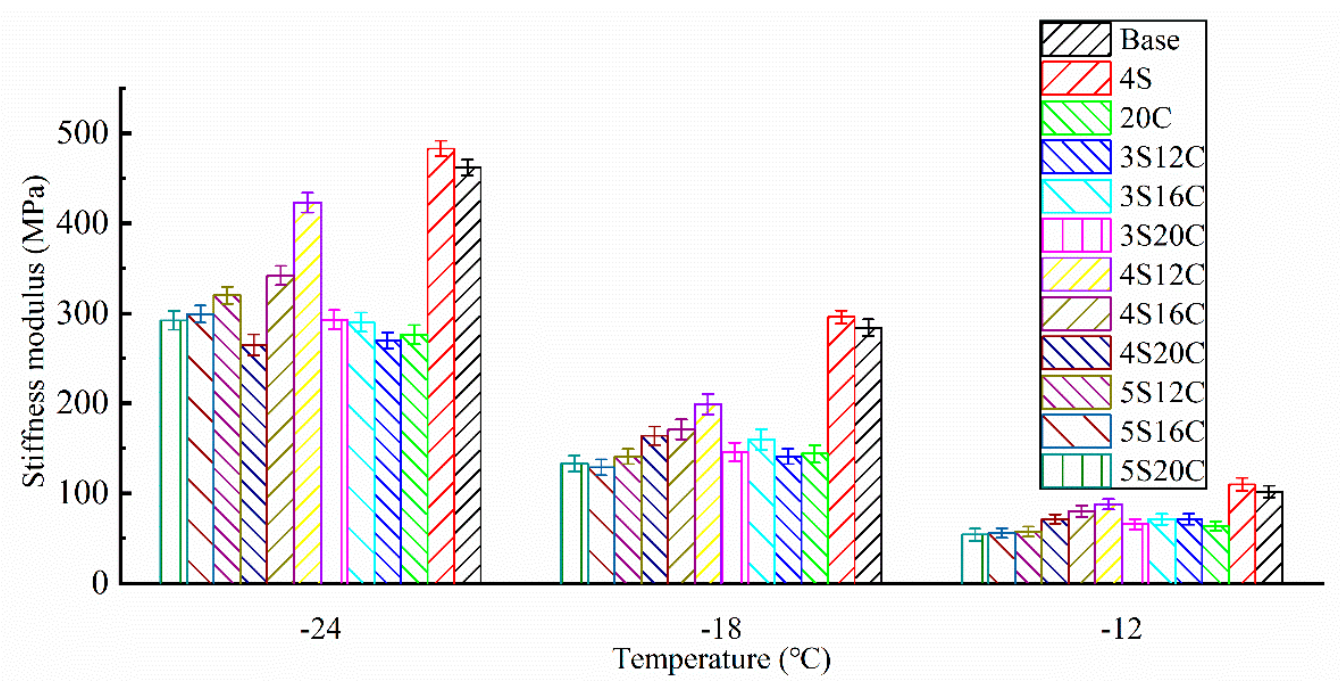

Figure 5. Stiffness modulus (S) of asphalt at different temperatures.

The stiffness modulus of $4 \mathrm{~S}$ is the highest and even slightly higher than that of base asphalt, which presents that the addition of $4 \%$ nano- $-\mathrm{SiO}_{2}$ makes asphalt stiffer and reduces the low-temperature cracking resistance of asphalt. The stiffness modulus of $20 \mathrm{C}$ is the lowest, because $20 \%$ rubber powder increases the elasticity of asphalt at low temperature. Consequently, rubber powder greatly improves the low-temperature property of asphalt. By keeping the content of nano- $\mathrm{SiO}_{2}$ the same, the stiffness modulus decreases with the increase of rubber powder content. By keeping the content of rubber powder the same, the largest stiffness modulus can be easily seen in $4 \%$ nano- $\mathrm{SiO}_{2}$. Thus, it is essential to solve the degradation on the low-temperature property of $4 \mathrm{~S}, 4 \mathrm{~S} 20 \mathrm{C}$ is the optimum compound ratio due to its smallest stiffness modulus among $4 \mathrm{~S} 12 \mathrm{C}, 4 \mathrm{~S} 16 \mathrm{C}$, and $4 \mathrm{~S} 20 \mathrm{C}$. This finding could be related to the network structure of rubber powder modified asphalt. $4 \%$ nano-SiO${ }_{2}$ seems to be a suitable dosage, which can be used as tiny particles to fill the defects in the network structure and make rubber powder modified asphalt well-distributed.

\section{Result Discussion of UV Aging Asphalt}

\subsection{Evaluation Indexes of Basic Properties}

From Figure $6 \mathrm{a}, \mathrm{b}$ it can be seen that the $C_{s p}$ of modified asphalt is less than that of base asphalt, and the $P_{\text {age }}$ of modified asphalt is greater than that of base asphalt. Results show that the modifiers enhance the UV aging resistance of asphalt and improved the durability of asphalt. 20C indicates that the rubber powder can improve the anti-UV aging of asphalt. It is due to the fact that a small amount of carbon black in rubber powder enters into asphalt during the shear to prepare rubber powder modified asphalt, and carbon black is known to absorb UV light slightly. 


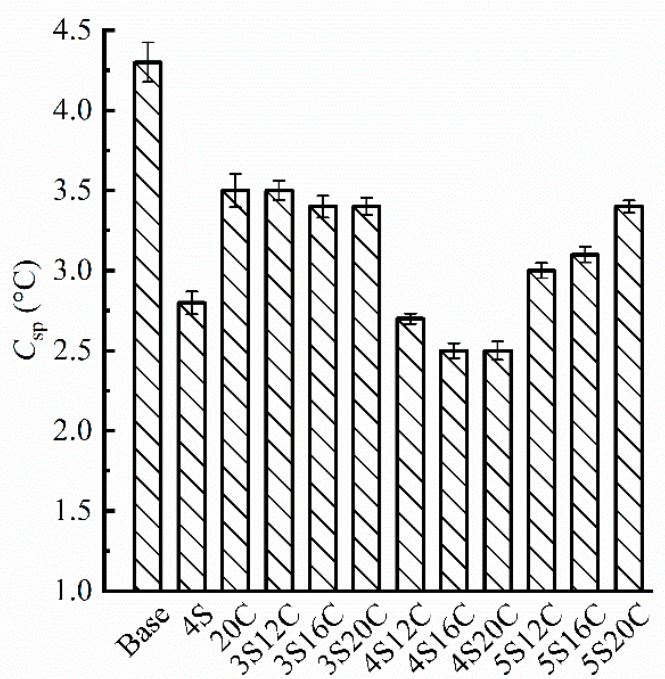

(a)

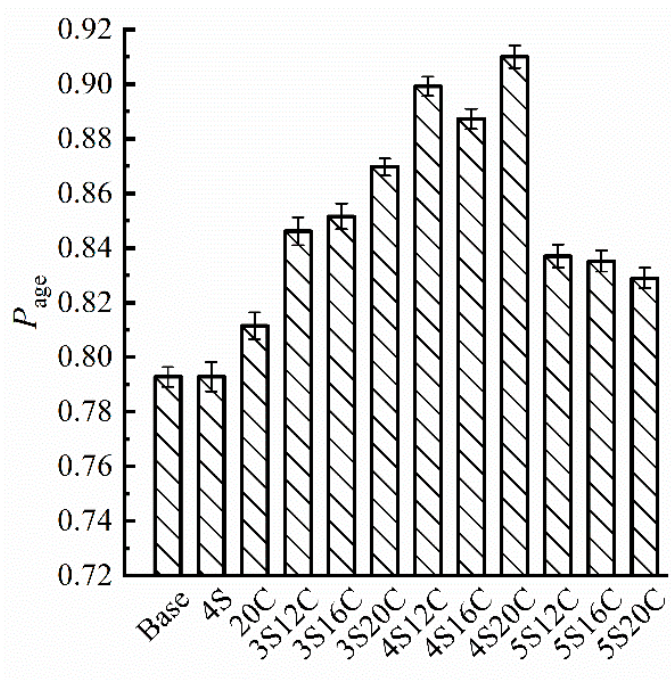

(b)

Figure 6. Evaluation indexes of basic properties: (a) the change of softening point $\left(C_{s p}\right)$, and (b) the change percent of penetration $\left(P_{\text {age }}\right)$.

However, the increase of rubber powder content does not significantly improve the UV aging resistance of modified asphalt when the nano- $\mathrm{SiO}_{2}$ content is the same. Moreover, the protection effect of asphalt on the UV-aging is more sensitive to nano-SiO${ }_{2}$, because of reflection of nano- $\mathrm{SiO}_{2}$ to the UV light. When the content of nano- $\mathrm{SiO}_{2}$ is $5 \%$, the UV-aging resistance of the compound modified asphalt is deteriorated, excessive agglomeration of nano- $\mathrm{SiO}_{2}$ affects the modification. In all group, 4S20C ranks as the best dosage to have the smallest $C_{s p}$ and the largest $P_{\text {age }}$, which depicts $4 \mathrm{~S} 20 \mathrm{C}$ presents the strongest resistance to UV aging on softening point and penetration.

\subsection{Evaluation Indexes of Rheological Properties}

\subsubsection{Brookfield Viscosity Aging Index}

Figure 7 shows that minor anti-UV aging effect can be seen in rubber powder modified asphalt (20C) due to the carbon black, because the $V_{\text {age }}$ of $20 \mathrm{C}$ is slightly lower than that of base asphalt. The $V_{\text {age }}$ of nano- $\mathrm{SiO}_{2}$ modified asphalt decreases sharply with respect to other groups, this finding indicates that nano- $\mathrm{SiO}_{2}$ can effectively improve the anti-UV aging property of asphalt. However, the $V_{\text {age }}$ starts to rise when nano- $\mathrm{SiO}_{2}$ content reaches $5 \%$. Additionally, the $V_{\text {age }}$ of $4 \mathrm{~S} 16 \mathrm{C}$ is the lowest, and the $V_{\text {age }}$ of $4 \mathrm{~S} 20 \mathrm{C}$ is very close to that of $4 \mathrm{~S} 16 \mathrm{C}$. 


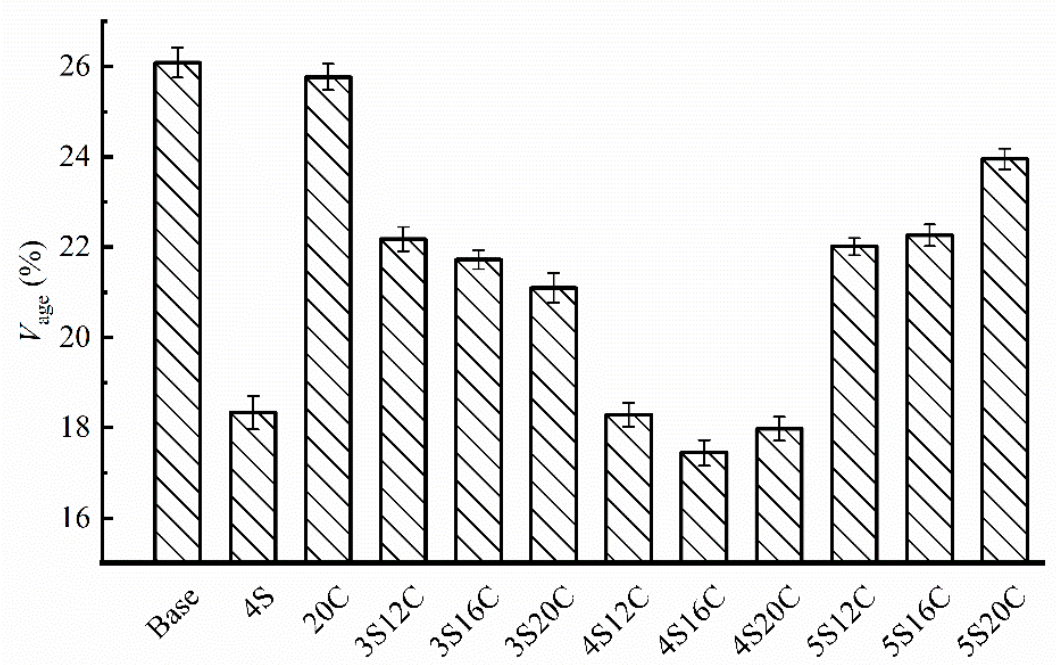

Figure 7. Brookfield viscosity aging index $\left(V_{\text {age }}\right)$ with different modifier content.

\subsubsection{Complex Modulus Aging Index}

The temperature sweep of each asphalt after UV aging was scanned at 10rad/s and within linear viscoelastic domain, and the $C_{\text {age }}$ is shown in Figure 8, the coefficient of variation of all data is less than 10\%. In Figure 8, obvious differences can be summarized between the base asphalt and modified asphalt. Otherwise, the influence of temperature on the $C_{\text {age }}$ seems to be random, especially at $70^{\circ} \mathrm{C}$.

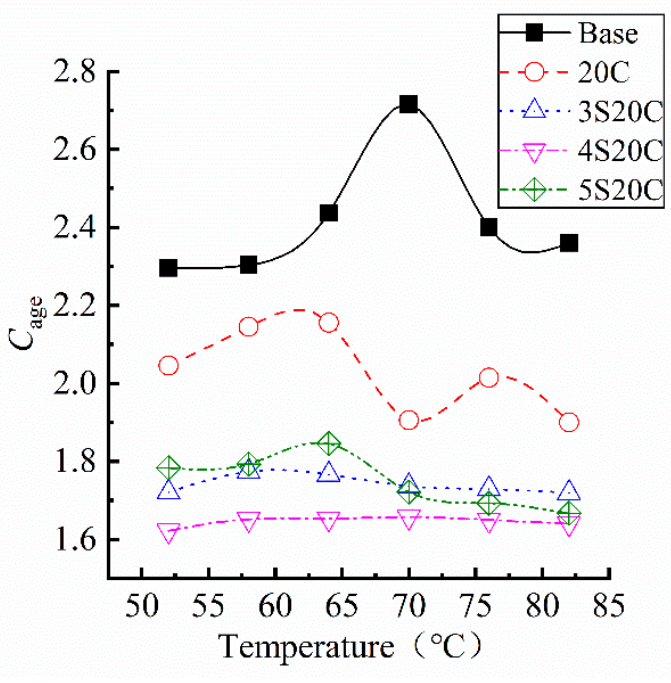

(a)

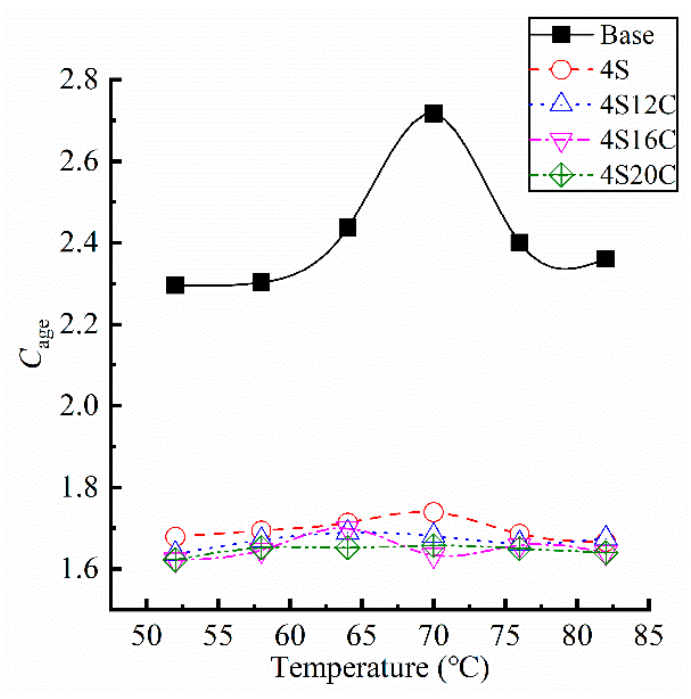

(b)

Figure 8. Complex modulus aging index $\left(C_{\text {age }}\right)$ of asphalt samples: (a) with different nano- $\mathrm{SiO}_{2}$, and (b) with different rubber powder.

The $C_{\text {age }}$ of modified asphalt is lower than that of the base asphalt, which proves that the incorporation of nano-SiO${ }_{2}$ and rubber powder improves the UV aging resistance of asphalt. It can be seen from Figure 8a that the $C_{\text {age }}$ curve of the rubber powder modified asphalt is located below that of the base asphalt, rubber powder has certain effect on the improvement of UV aging resistance. With the influence of nano- $\mathrm{SiO}_{2}$, the $C_{\text {age }}$ decreases significantly. When the content of nano- $\mathrm{SiO}_{2}$ is $4 \%$, the $C_{\text {age }}$ is the lowest, and the anti-UV aging resistance is enhanced to a large degree. Figure $8 \mathrm{~b}$ presents that the $C_{\text {age }}$ of compound modified asphalt behaves almost the same. It proves that nano- $\mathrm{SiO}_{2}$ is the main component to play anti-UV aging role. 


\subsubsection{Stiffness Modulus Aging Index}

As shown in Figure 9, the $S_{\text {age }}$ of all testing groups subjected to UV aging is greater than 1. Asphalt becomes brittle and hard as the stiffness modulus becomes larger, and the low-temperature cracking will be more likely to occur on asphalt pavement. The $S_{\text {age }}$ of modified asphalt is smaller than that of the base asphalt, which implies that nano-SiO${ }_{2}$ and rubber powder can protect the UV aging degradation on the low-temperature property of asphalt. In Figure 9a, the $S_{\text {age }}$ of nano- $\mathrm{SiO}_{2}$ modified asphalt present obvious decrease than that of the base asphalt and 20C. Figure $9 \mathrm{~b}$ expresses that the $S_{\text {age }}$ of $4 \mathrm{~S} 12 \mathrm{C}, 4 \mathrm{~S} 16 \mathrm{C}$, and $4 \mathrm{~S} 20 \mathrm{C}$ almost behave the same at $-24^{\circ} \mathrm{C}$ and $-18^{\circ} \mathrm{C}$, which directs that the rubber powder is not sensitive to stiffness modulus increase due to UV aging. It is obvious that $4 \mathrm{~S} 20 \mathrm{C}$ must be chosen as the best compound ratio related to the lowest increase of stiffness modulus.

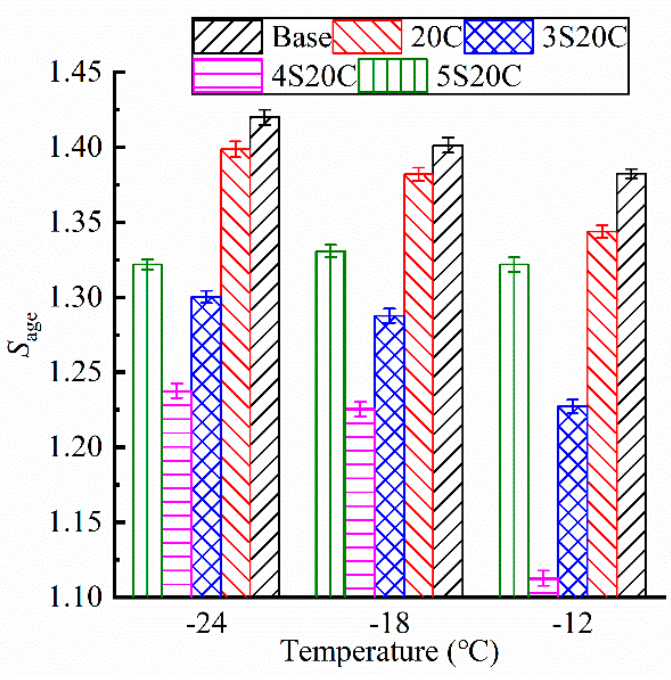

(a)

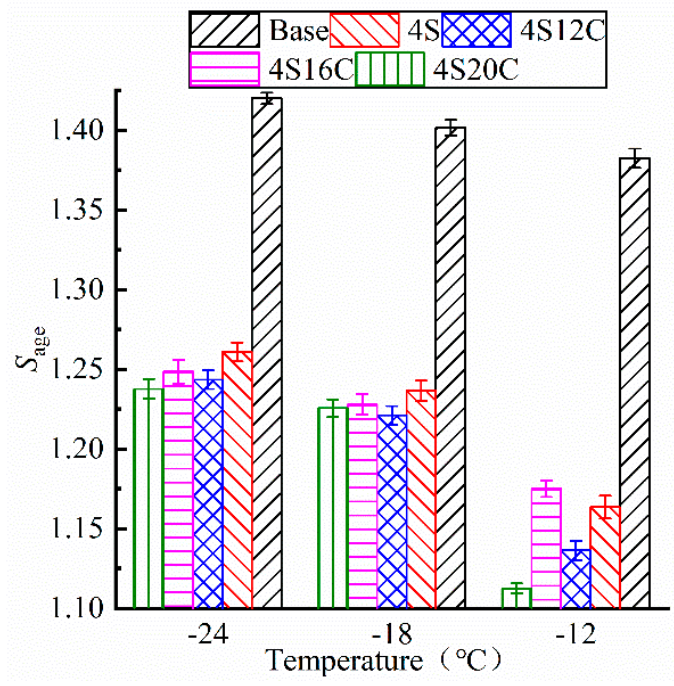

(b)

Figure 9. Stiffness modulus aging index $\left(S_{\text {age }}\right)$ of asphalt with different modifier content: (a) with different nano- $\mathrm{SiO}_{2},(\mathbf{b})$ with different rubber.

\section{Conclusions}

Property evaluation of the non-aged asphalt indicates that the compound modification improves the high-temperature stability of asphalt significantly, and the effect of compound modification becomes more obvious than the single-doped modification. $\mathrm{Nano-SiO} \mathrm{S}_{2}$ plays an adverse role on the low-temperature cracking of asphalt, because of the slightly increase of stiffness modulus. Contrarily, rubber powder increases the elasticity and decreases the stiffness modulus of asphalt at low temperatures. Therefore, the compound modification might solve the low-temperature cracking issue due to the nano- $\mathrm{SiO}_{2}$. Additionally, $4 \%$ nano- $\mathrm{SiO}_{2}$ and $20 \%$ rubber powder compound modified asphalt (4S20C) presents the best performance in this study.

By directly exposing to UV aging, compound modification is proved to improve the anti-UV aging performance of asphalt. As the dosage of nano- $\mathrm{SiO}_{2}$ changes, the aging degree of asphalt fluctuates significantly. However, the effect of rubber powder on anti-UV aging is concluded to be less sensitive. Nano- $\mathrm{SiO}_{2}$ performs a predominant role on enhancing the UV aging resistance. Moreover, $4 \%$ nano- $\mathrm{SiO}_{2}$ and $20 \%$ rubber powder compound modified asphalt (4S20C) is testified to be the optimum dosage in this study, due to its improvement on the UV aging resistance and elimination of the low-temperature property degradation caused by nano- $\mathrm{SiO}_{2}$.

Author Contributions: Conceptualization, G.Q. and X.G.; data curation, C.Y. and H.Y.; methodology, G.Q., X.G. and H.Y.; original draft, C.Y. and H.H.; review and editing, G.Q., C.Y. and X.G. All authors have read and agreed to the published version of the manuscript. 
Funding: The study was supported by National Natural Science Foundation of China (grant No.: 51808058, and 51778071). The study was also supported by Open Fund of State Engineering Laboratory of Highway Maintenance Technology (Changsha University of Science \& Technology) (grant No.: kfj170102).

Acknowledgments: This study was completed the School of Traffic and Transportation Engineering, in Changsha University of Science \& Technology.

Conflicts of Interest: The authors declare no conflict of interest.

\section{References}

1. Ghavibazoo, A.; Abdelrahman, M.; Ragab, M. Effect of Crumb Rubber Modifier Dissolution on Storage Stability of Crumb Rubber-Modified Asphalt. Transp. Res. Rec. J. Transp. Res. Board 2013, 2370, $109-115$. [CrossRef]

2. Jin, J.; Liu, L.; Liu, R.; Wei, H.; Qian, G.; Zheng, J.; Xie, W.; Lin, F.; Xie, J. Preparation and thermal performance of binary fatty acid with diatomite as form-stable composite phase change material for cooling asphalt pavements. Constr. Build. Mater. 2019, 226, 616-624. [CrossRef]

3. Liu, H.; Yang, X.; Jiang, L.; You, L.; Huang, T.; Yang, Y. Fatigue-creep damage interaction model of asphalt mixture under the semi-sine cycle loading. Constr. Build. Mater. 2020, 251, 119070. [CrossRef]

4. Wang, D.; Falchetto, A.C.; Riccardi, C.; Poulikakos, L.; Hofko, B.; Porot, L.; Wistuba, M.P.; Baaj, H.; Mikhailenko, P.; Moon, K.H. Investigation on the combined effect of aging temperatures and cooling medium on rheological properties of asphalt binder based on DSR and BBR. Road Mater. Pavement Des. 2019, 20, S409-S433. [CrossRef]

5. Qian, G.; Yu, H.; Jin, D.; Bai, X.; Gong, X. Different water environment coupled with ultraviolet radiation on ageing of asphalt binder. Road Mater. Pavement Des. 2020, 1-14. [CrossRef]

6. Koyun, A.; Büchner, J.; Wistuba, M.P.; Grothe, H. Rheological, spectroscopic and microscopic assessment of asphalt binder ageing. Road Mater. Pavement Des. 2020, 1-18. [CrossRef]

7. Yu, H.; Bai, X.; Qian, G.; Wei, H.; Gong, X.; Jin, J.; Li, Z. Impact of Ultraviolet Radiation on the Aging Properties of SBS-Modified Asphalt Binders. Polymers 2019, 11, 1111. [CrossRef] [PubMed]

8. Jin, J.; Tan, Y.; Liu, R.; Zheng, J.; Zhang, J. Synergy Effect of Attapulgite, Rubber, and Diatomite on Organic Montmorillonite-Modified Asphalt. J. Mater. Civ. Eng. 2019, 31, 04018388. [CrossRef]

9. Cheraghian, G.; Wu, Q.; Mostofi, M.; Li, M.-C.; Afrand, M.; Sangwai, S.J. Effect of a novel clay/silica nanocomposite on water-based drilling fluids: Improvements in rheological and filtration properties. Colloids Surfaces A Physicochem. Eng. Asp. 2018, 555, 339-350. [CrossRef]

10. Yang, J.; Tighe, S.L. A Review of Advances of Nanotechnology in Asphalt Mixtures. Procedia Soc. Behav. Sci. 2013, 96, 1269-1276. [CrossRef]

11. Yu, J.; Ren, Z.; Yu, H.; Wang, D.; Svetlana, S.; Korolev, E.; Gao, Z.; Guo, F. Modification of Asphalt Rubber with Nanoclay towards Enhanced Storage Stability. Materials 2018, 11, 2093. [CrossRef] [PubMed]

12. Jin, J.; Chen, B.; Liu, L.; Liu, R.; Qian, G.; Wei, H.; Zheng, J.-L. A Study on Modified Bitumen with Metal Doped Nano-TiO2 Pillared Montmorillonite. Materials 2019, 12, 1910. [CrossRef] [PubMed]

13. Cheraghian, G.; Falchetto, A.C.; You, Z.; Chen, S.; Kim, Y.S.; Westerhoff, J.; Moon, K.H.; Wistuba, M.P. Warm mix asphalt technology: An up to date review. J. Clean. Prod. 2020, 268, 122128. [CrossRef]

14. Zhang, L.; Hajikarimi, P.; Rahi, M.; Nejad, F.M. Physiochemical, Rheological, and Oxidative Aging Characteristics of Asphalt Binder in the Presence of Mesoporous Silica Nanoparticles. J. Mater. Civ. Eng. 2016, 28, 04015133. [CrossRef]

15. Cheraghian, G.; Wistuba, M.P. Ultraviolet aging study on bitumen modified by a composite of clay and fumed silica nanoparticles. Sci. Rep. 2020, 10, 1-17. [CrossRef]

16. Yao, H.; You, Z.; Li, L.; Lee, C.H.; Wingard, D.; Yap, Y.K.; Shi, X.; Goh, S.W. Rheological Properties and Chemical Bonding of Asphalt Modified with Nanosilica. J. Mater. Civ. Eng. 2013, 25, 1619-1630. [CrossRef]

17. Shafabakhsh, G.; Mirabdolazimi, S.; Sadeghnejad, M. Evaluation the effect of nano-TiO2 on the rutting and fatigue behavior of asphalt mixtures. Constr. Build. Mater. 2014, 54, 566-571. [CrossRef]

18. Shafabakhsh, G.; Ani, O.J. Experimental investigation of effect of Nano TiO2/SiO2 modified bitumen on the rutting and fatigue performance of asphalt mixtures containing steel slag aggregates. Constr. Build. Mater. 2015, 98, 692-702. [CrossRef] 
19. Qian, G.; Yu, H.; Gong, X.; Zhao, L. Impact of Nano-TiO2 on the NO2 degradation and rheological performance of asphalt pavement. Constr. Build. Mater. 2019, 218, 53-63. [CrossRef]

20. Ashish, P.K.; Singh, D. Development of empirical model for predicting G*/Sin $\delta$ and viscosity value for nanoclay and Carbon Nano Tube modified asphalt binder. Constr. Build. Mater. 2018, 165, 363-371. [CrossRef]

21. Wang, T.; Xiao, F.; Zhu, X.; Huang, B.; Wang, J.; Amirkhanian, S. Energy consumption and environmental impact of rubberized asphalt pavement. J. Clean. Prod. 2018, 180, 139-158. [CrossRef]

22. Xiang, L.; Cheng, J.; Kang, S. Thermal oxidative aging mechanism of crumb rubber/SBS composite modified asphalt. Constr. Build. Mater. 2015, 75, 169-175. [CrossRef]

23. Pang, L.; Liu, K.; Wu, S.; Lei, M.; Chen, Z. Effect of LDHs on the aging resistance of crumb rubber modified asphalt. Constr. Build. Mater. 2014, 67, 239-243. [CrossRef]

24. Xiao, F.; Amirkhanian, S.; Putman, B.; Shen, J. Laboratory investigation of engineering properties of rubberized asphalt mixtures containing reclaimed asphalt pavement. Can. J. Civ. Eng. 2010, 37, 1414-1422. [CrossRef]

25. Ma, Y.; Hu, W.; Polaczyk, P.A.; Han, B.; Xiao, R.; Zhang, M.; Huang, B. Rheological and aging characteristics of the recycled asphalt binders with different rejuvenator incorporation methods. J. Clean. Prod. 2020, 262, 121249. [CrossRef]

26. Saltan, M.; Terzi, S.; Karahancer, S. Examination of hot mix asphalt and binder performance modified with nano silica. Constr. Build. Mater. 2017, 156, 976-984. [CrossRef]

27. Saltan, M.; Terzi, S.; Karahancer, S. Performance analysis of nano modified bitumen and hot mix asphalt. Constr. Build. Mater. 2018, 173, 228-237. [CrossRef]

28. Bhat, F.S.; Mir, M.S. Performance evaluation of nanosilica-modified asphalt binder. Innov. Infrastruct. Solutions 2019, 4, 63. [CrossRef]

29. Shi, X.; Cai, L.; Xu, W.; Fan, J.; Wang, X. Effects of nano-silica and rock asphalt on rheological properties of modified bitumen. Constr. Build. Mater. 2018, 161, 705-714. [CrossRef]

30. Rezaei, S.; Ziari, H.; Nowbakht, S. Low temperature functional analysis of bitumen modified with composite of nano-SiO 2 and styrene butadiene styrene polymer. Pet. Sci. Technol. 2016, 34, 415-421. [CrossRef]

31. Tanzadeh, J.; Shahrezagamasaei, R. Laboratory Assessment of Hybrid Fiber and Nano-silica on Reinforced Porous Asphalt Mixtures. Constr. Build. Mater. 2017, 144, 260-270. [CrossRef]

32. Kiser, J.V.L. Asphalt rubber: Overcoming the obstacles. Scrap 2003, 46-52.

33. Abdelmagid, A.A.A.; Feng, C.P. Evaluating the Effect of Rice-Husk Ash and Crumb-Rubber Powder on the High-Temperature Performance of Asphalt Binder. J. Mater. Civ. Eng. 2019, 31, 04019296. [CrossRef]

34. Zhang, L.; Xing, C.; Gao, F.; Li, T.-S.; Tan, Y.-Q. Using DSR and MSCR tests to characterize high temperature performance of different rubber modified asphalt. Constr. Build. Mater. 2016, 127, 466-474. [CrossRef]

35. Navarro, F.; Partal, P.; Martínez-Boza, F.; Valencia, C.; Gallegos, C. Rheological characteristics of ground tire rubber-modified bitumens. Chem. Eng. J. 2002, 89, 53-61. [CrossRef]

36. Xuanrui, G. Research on the influence factors of asphalt rubber mixture fatigue performance. In Proceedings of the IEEE International Conference of Online Analysis and Computing Science (ICOACS), Chongqing, China, 28 May 2016.

37. China Ministry of Transport. JT/T 798-2011 Asphalt Rubber for Highway Engineering; China Communications Press: Beijing, China, 2011.

Publisher's Note: MDPI stays neutral with regard to jurisdictional claims in published maps and institutional affiliations.

(C) 2020 by the authors. Licensee MDPI, Basel, Switzerland. This article is an open access article distributed under the terms and conditions of the Creative Commons Attribution (CC BY) license (http://creativecommons.org/licenses/by/4.0/). 